\title{
Fontes para a história indígena do e antes do século XVI
}

Ana Carolina Sodré Ferreira

\section{Resumo}

O artigo buscou problematizar os tipos de fontes históricas utilizadas para a reconstrução da história dos povos indígenas do e antes do século XVI a partir de exemplos de dois referenciais que trabalham com a memória e com a arqueologia e a antropologia. Buscou-se, ainda, apresentar outros campos do conhecimento, principalmente o da arqueologia, com os quais a História necessita dialogar para encontrar uma solução para a problemática da construção de uma historiografia indígena do e antes do século XVI sob uma perspectiva menos europeizante e mais próxima da indígena. Ao final do artigo foram propostas quatro medidas que podem ser adotadas para tentar solucionar esta problemática.

Palavras-chave: Fontes para a história indígena - História indígena - Brasil colonial. 


\section{História e memória}

\section{I.I. Uma narrativa dos conflitos indígenas a partir de Gabriel Soares de Sousa ${ }^{\mathrm{I}}$}

No litoral da região sudeste do território, um povo descendente dos tupinambás, os tamoios ${ }^{2}$, dominava a região que compreendia desde o então rio do Cabo de São Tomé até Angra dos Reis. Como guerreavam constantemente com os povos vizinhos, não possuíam aliados próximos. Com o início da colonização portuguesa e a invasão francesa na região durante o século XVI, os tamoios acabaram sendo expulsos para o sertão (interior do território).

À época da chegada dos portugueses no futuro território do Brasil, em I500, os indígenas que habitavam o nordeste da costa brasileira pertenciam à etnia tupinambá, cujo domínio fora resultado de seu processo de expansão em direção ao litoral. Antes da hegemonia dos tupinambás, outros povos já haviam dominado esta região.

De acordo com relatos indígenas ouvidos por Sousa ([20--?]), os tapuias ${ }^{3}$ teriam sido a "tribo indígena" 4 mais antiga que havia habitado e dominado a costa brasileira, desde os atuais rio da Prata até o rio Amazonas, antes de serem expulsos pelos tupinaés para o sertão. Durante o período de dominação dos tapuias na costa nordeste brasileira, estes tornaram-se inimigos de muitos grupos indígenas nas guerras que travavam para defender sua dominação do litoral. Após sua expulsão e deslocamento para o sertão, os tapuias ainda continuaram a ser inimigos de todos os povos indígenas próximos, principalmente dos tupinaés e dos tupinambás.

I Toda a subseção, cada parágrafo narrativo, tem como referência o Tratado descritivo do Brasil em 1587, de Gabriel Soares de Sousa ([20--?]). A obra consultada é uma edição traduzida disponibilizada online pelo site governamental Domínio Público. Disponível em http>//www.dominiopublico.gov.br.

2 "[...] de quem se fazem parentes, cuja fala se parece muito uma com a outra, e têm as mesmas gentilidades, vida e costumes, e são amigos um dos outros" (SOUSA, [20--?], p. IIO).

3 Os tapuias não correspondiam a uma etnia indígena, mas, sim, a um conjunto composto por diferentes grupos étnicos que não falavam a língua tupi-guarani; logo, durante a sua presença no litoral, diferentes povos indígenas controlavam o território e, devido à sua hegemonia até a chegada do tupinaés, pode-se supor que esses povos viviam em estado bélico mínimo entre si, já que possuíram o controle da costa por um período significativo de tempo. Os aimorés são um exemplo de "grupo étnico tapuia", sendo que, no decorrer dos séculos, receberem diferentes denominações pelos portugueses e residentes do Brasil 4 Sobre a análise e problematização do termo tribo, vide os seguintes trabalhos de Maurice Godelier: Les tribus dans l'histoire et face aux États (2010) e o capítulo 40 conceito de tribo: crise de um conceito ou crise dos fundamentos empíricos da antropologia? do livro Horizontes da antropologia (I973). 
Os novos "donos" do litoral nordestino, os tupinaés, eram chamados de "taburas" 5 pelos seus inimigos em decorrência das guerras que promoviam para aterrorizar os povos da região. As razões que motivaram os tupinaés a cobiçar os domínios dos tapuias - abundância de terras, proximidade com o oceano e fertilidade dos solos -, também impulsionaram outro povo a direcionar-se a esta região: os tupinambás vieram de além do atual rio São Francisco e promoveram guerras destruidoras contra os tupinaés a ponto de obrigá-los a se refugiarem no sertão, sendo que as guerras entre tupinaés e tapuias no sertão se intensificaram e levaram estes últimos a adentrar ainda mais no interior do território.

Apesar dos tupinambás terem expulsado seus inimigos e continuado a vencer as batalhas contra estes para manterem a dominação do território conquistado, eles não puderam evitar uma guerra interna: devido a diferenças, o povo tupinambá sofreu diversas dissidências que levaram à formação de aldeias assentadas - já no período de colonização e povoamento do território pelos portugueses - entre os então rio São Francisco e rio Real, que se declaravam inimigas das aldeias estabelecidas no rio Real até a capitania da Bahia de Todos os Santos.

As guerras entre estas aldeias assimilavam-se, em termos de brutalidade, com as guerras entre os tupinambás e seus inimigos, pois havia mortes, antropofagia e escravização do vencido. Na época de povoamento da Bahia de Todos os Santos, os moradores da capitania declararam inimigos os tupinambás localizados do outro lado desta, no limite do rio de Paraguaçu e do Sergipe. Neste período, novas dissidências tupinambás continuaram a surgir, intensificando, consequentemente, o estado bélico da capitania.

A divisão entre os tupinambás, porém, não se iniciou com sua dominação do litoral nordestino: nota-se uma certa normalidade na existência desse tipo de cisão no decorrer da história das sociedades indígenas. Os tupinambás e os tupinaés, por exemplo, já foram um único povo, mas depois se tornaram grandes inimigos e, como salienta Sousa, "Tupinaés são uma gente do Brasil semelhante no parecer, vida e costumes dos tupinambás e na linguagem não têm mais diferença uns dos outros" ([20--?], p. 333).

As dissidências internas também acompanharam os tapuias quando estes refugiaram-se no sertão: com a expulsão do litoral, conflitos e inimizades in-

5 "Contrários". Denominação utilizada posteriormente pelos portugueses para se referir a um povo indígena inimigo de outro (SOUSA, [20--?]). 
ternas intensificaram-se, levando à separação dos tapuias em diversos grupos espalhados pelo sertão, que tinham linguagem e costumes pouco ou muito diferentes entre si. A fragmentação dos povos tapuias contribuiu para o seu enfraquecimento nas guerras contra seus inimigos externos. Mesmo descendendo de um mesmo povo, os grupos tapuias que se formaram participaram de guerras sangrentas entre si.

Ainda durante o período de soberania dos tupinaés no litoral nordestino, estes dividiam o território com outro povo indígena, localizado mais ao sul do território: os tupiniquins.

Embora tenham guerreado algumas vezes entre si, estes povos não eram inimigos: eles descendiam do mesmo tronco, havendo muitos tupiniquins misturados com os tupinaés. Com o início da expansão dos tupinambás, os tupiniquins se viram cercados por estes de um lado, e pelos aimorés, também inimigos, de outro; inevitavelmente, muitos refugiaram-se no sertão. Os primeiros portugueses povoadores das capitanias de Porto Seguro, Ilhéus e Espírito Santo, depararam-se com este povo e chegaram a travar guerras contra este, contudo, posteriormente, fizeram as pazes e os tupiniquins passaram a ser considerados amigos dos portugueses. Todavia, a migração forçada em direção ao interior continuou, mas agora os tupiniquins fugiam do mau tratamento recebido dos portugueses por serem considerados "pouco tementes a Deus" (SOUSA, [20--?], p. 87).

\section{I.II. As problemáticas da narrativa de Sousa e de outras fontes europeias}

A narrativa citada é baseada no clássico Tratado descritivo do Brasil em 1587, no qual seu autor, Gabriel Soares de Sousa, tentou reconstruir a história dos povos indígenas que mantiveram contato com os portugueses ao longo do século XVI.

Ao lado do livro de Sousa, obras como as de Pero de Magalhães Gândavo (I576), Hans Staden (I557), André Thevet (I557) e Jean de Léry (I578), além das cartas jesuíticas escritas pelos padres Manuel da Nóbrega, José de Anchieta, João de Azpilcueta-Navarro, Antônio Pires e demais membros da Companhia de Jesus que compuseram as missões jesuíticas enviadas ao Brasil, constituem fontes potenciais para a reconstrução da história indígena do século XVI, possuindo, porém, um fator limitante em comum: são fontes produzidas por europeus sob a perspectiva europeia sobre os povos indígenas com os quais entraram em contato. 
As informações contidas na breve narrativa anteriormente recontada sobre um fragmento da história bélica das sociedades indígenas do litoral, foram obtidas por Sousa ([20--?]) a partir de conversas com índios, como ele próprio admite em algumas passagens de seu livro. Em outras palavras, ele fez uso das memórias de indígenas transmitidas através da oralidade para elaborar uma história escrita e, ao fazer isso, Sousa perpetuou um fragmento da memória indígena na escrita e criou uma obra clássica que, quase 500 anos depois, ainda permanece uma fonte de relevância. Curiosamente, nota-se que um dos referenciais mais utilizados nas pesquisas sobre os povos indígenas do século XVI teve como fonte primordial para sua construção o que hoje denominamos de "memórias históricas" 6 .

O panorama geral dado por Sousa sobre os povos indígenas do litoral antes da chegada dos europeus pode se tornar uma armadilha para o leitor desatento. Primeiramente, deve-se levar em consideração o fato de Sousa ter escrito sua obra décadas depois da chegada e do estabelecimento dos portugueses no Brasil - logo, uma nova fase na história dos povos indígenas havia se iniciado. Em segundo lugar, a narrativa de Sousa carece de precisão cronológica: ele mistura, por exemplo, a narração de guerras entre grupos indígenas antes e depois da chegada dos europeus, sugerindo, equivocadamente, que a dinâmica, organização e motivações das guerras indígenas não se alteraram com o estabelecimento de contato com os europeus ${ }^{7}$. Sousa ainda é anacrônico ao dar nomes consagrados por portugueses a regiões e rios anteriores à sua chegada e citar regiões que não existiam nessa época - a exemplo de "Bra-

6 Sá define o termo da seguinte maneira: "Nos termos de uma 'psicologia social da memória', as 'memórias históricas' são entendidas como 'memórias da história', isto é, memórias construídas por populações que viveram ou estiveram implicadas em fatos que vieram a se tornar 'históricos'” (20I5, p. 268). Deve-se ressaltar que os acontecimentos narrados por Sousa sobre os conflitos bélicos entre os povos indígenas não se constituem em fatos históricos na historiografia brasileira sobre o Brasil. Tais acontecimentos poderiam vir a se tornar fatos históricos, por exemplo, se existisse uma historiografia indígena consolidada e que não se "iniciasse" em I500. Ademais, Sousa não possuía consciência de uma história da memória se se levar em consideração o fato de a História como disciplina e suas metodologias, não serem consideradas ciência no século XVI.

7 A guerra constituía uma das principais atividades desenvolvidas por boa parte dos povos indígenas. Com a chegada dos europeus, os povos indígenas identificaram vantagens em estabelecer alianças com estes para o uso de ferramentas e armas europeias - superiores às indígenas - nas guerras contra seus inimigos. Com armas de maior poder de destruição, é possível supor que o nível bélico dos povos indígenas se elevou significativamente, bem como as destruições provenientes da guerra (mortes, escravização, conquista de territórios, fome). Para saber mais sobre o assunto, vide a obra A função social da guerra na sociedade Tupinambá (I952), de Florestan Fernandes. 
sil”. E, por último, há a generalização das várias sociedades indígenas existentes no litoral: embora haja o reconhecimento da diversidade desses povos, a narrativa logo se generaliza ao reduzir a diversidade em termos como "índios tapuias". Desta forma, apesar de útil, a obra de Sousa é insuficiente para uma compreensão e um conhecimento amplo da realidade cultural e histórica indígena do e antes do século XVI.

Mas se existem somente fontes escritas europeias sobre o período, é realmente possível reconstruir a história dos povos indígenas sob uma perspectiva menos europeizante e mais próxima da realidade de seu tempo? O diálogo da História com outras áreas do conhecimento e o uso de fontes alternativas (não somente fontes e documentos escritos) podem possibilitar esta reconstrução. $\mathrm{E}$, em se tratando das histórias dos povos indígenas, elas adquirem grande importância em detrimento da fonte textual ${ }^{8}$. No entanto, quando se observam os depoimentos orais de indígenas utilizados por Sousa, nota-se que o uso da memória como fonte histórica pode se apresentar problemática em termos cronológicos e da falta de comprovação física (por exemplo: documentos e relatos escritos). Mas se a memória pertence ao indivíduo e este, por sua vez, se constitui agente e testemunha do processo histórico de seu tempo, então a memória já não possuiria a sua validação empírica?

Há diversos conflitos entre aqueles que fazem uso da memória e aqueles que fazem uso das práticas científicas da História para a reconstrução do passado. Sá (20I5), por exemplo, destaca a falta de rigor científico e compromisso com a ética do historiador por parte da memória. Sá levanta, ainda, outras problemáticas para a análise da relação entre memória e história: em vista da natureza científica da História, esta tende a impor uma noção de "história verdadeira e única", enquanto a memória, construída por diferentes membros da sociedade, é múltipla, sugerindo, desta forma, uma visão inclusiva e democrática do uso da memória na reconstrução do passado. Hartog (apud BÔAS,

8 A ausência de uma literatura produzida pelos próprios povos indígenas antes e depois da colonização possui diversas possíveis justificativas: ausência de uma cultura escrita; não inclusão ou inclusão tardia dos povos indígenas à sociedade colonizadora, impossibilitando, assim, o acesso a instituições e direitos; isolamento de povos indígenas; negligência de instituições de ensino e de pesquisa e do Estado em relação aos estudos indígenas; tradição historiográfica brasileira caracterizada pela marginalização dos indígenas na reconstrução da história do Brasil; falta de políticas públicas que promovam a alfabetização entre os povos indígenas e que possibilitem, assim, a apropriação da língua portuguesa por estes de forma que possam se expressar através de sua escrita e fala; existência de poucos núcleos - de grande porte - de pesquisa linguística e etnográfica de povos indígenas e a progressiva disseminação de tais núcleos; entre outros fatores. 
20I5), além de valorizar o potencial do uso da memória, destaca, também, a importância da testemunha nas discussões entre história e memória.

Em vista das escassas fontes indígenas, da marginalização imposta aos povos indígenas desde o início da colonização e das dificuldades ainda existentes nos dias atuais de reconhecimento de direitos dessas populações e da inclusão do indígena nos diferentes setores da sociedade, inevitavelmente a memória se torna a principal fonte histórica que permite a reconstrução da história dos povos indígenas. Se a testemunha e a memória são fatores integrantes e de importância no procedimento de construção da história, então se torna necessário fazer uso desses métodos na reconstrução da história ao invés de menosprezá-los e excluí-los.

No século XX, o historiador malinês Amadou Hampaté Bá demonstrou a validade científica do uso da tradição oral na reconstrução da história. Durante mais de $\mathrm{I} 5$ anos, Hampaté Bá ouviu centenas de relatos orais e, fazendo uso de metodologias da História, reconstruiu a história do Império Peul de Macina por meio de fontes orais, da memória transmitida de geração a geração. Ao término da longa pesquisa, o historiador chegou à conclusão de que a tradição oral era tão válida e científica quanto as fontes escritas:

Constatei que, no conjunto, meus mil informantes haviam respeitado a verdade dos fatos. A trama da narrativa era sempre a mesma. As diferenças, que se encontravam apenas em detalhes sem importância, deviam-se à qualidade da memória ou da verve peculiar do narrador. Dependendo do grupo étnico a que pertencia, podia tender a minimizar certos revezes ou a tentar encontrar alguma justificativa para eles, mas não mudava os dados básicos [...] Essa experiência provou-me que a tradição oral era perfeitamente válida do ponto de vista científico (HAMPATÉ BÁ, 20I0, p.207).

Deve-se destacar que Hampaté Bá pertencia a uma etnia africana, possuindo uma determina cultura africana, e estava inserido nas diferentes realidades de seu país e de seu continente. Diferentemente do continente africano, a população nativa do Brasil - a diversificada população indígena - perdeu sua supremacia no território para os portugueses, em termos numéricos principalmente, ao longo dos séculos. Diante deste cenário, poderá ter sobrevivido uma tradição oral indígena semelhante à das sociedades africanas, capaz de reconstruir uma história quase milenar? A resposta a esta pergunta somente será obtida quando estudos sobre a tradição oral indígena começarem a ser realizados e disseminados, bem como o seu uso na construção de conhecimentos históricos para averiguação de seu potencial como fonte. 


\section{História, Arqueologia e outras possibilidades}

Em sua obra A ferro e fogo, Warren Dean (2004) reconstrói uma "pré-história" da ocupação da região da Mata Atlântica com base em dados antropológicos e arqueológicos, ao mesmo tempo que fornece, indiretamente, subsídios para a (re)construção de uma história da alimentação nesta região. Como discorre, a Mata Atlântica nesse período tornou-se um polo de atração de migrações por ofertar condições favoráveis de sobrevivência, como clima favorável e abundância de animais. Tamanha abundância de seres fez surgir a hipótese de que a primeira leva de habitantes gerou a extinção de várias espécies devido à existência de uma caça sem limites, o que pode ser explicado, em parte, pela dificuldade de se encontrar rios produtivos - em quantidades suficientes - na Mata Atlântica nos quais se pudesse ser praticada a pesca. Não surpreende, no caso do Brasil, a tendência de grupos humanos de, ao longo da história, terem se deslocado para o litoral, pois é lá que se concentrava a fértil Mata Atlântica e onde há o acesso ao oceano - ou seja, à pesca.

Vestígios arqueológicos encontrados ao longo do litoral brasileiro que apontam para a presença humana, em tempo remotos, caracterizada, por exemplo, pela prática da pesca e da coleta, não poderiam fornecer subsídios para estudos históricos a respeito da ocupação do litoral por sociedades indígenas antes de I500? Como sobre a dinâmica de ocupação territorial, organização social e relações da prática da pesca e da coleta, e a relação destes com conflitos bélicos pela disputa da ocupação e domínio do litoral? Como discorrido no início deste artigo, de acordo com as memórias de indígenas ouvidas por Sousa, existiam, sim, guerras entre povos indígenas pelo domínio do litoral. Desta forma, os sítios arqueológicos não representariam grande potencial de fontes históricas para a condução desses estudos? Não seria a arqueologia um campo de amparo ao uso da tradição oral indígena na reconstrução da história dos índios do Brasil?

Desde o século XIX ${ }^{9}$, a Arqueologia se mostrou ser uma grande aliada na compreensão das culturas indígenas, tendo, desde então, descoberto centenas de vestígios arqueológicos indígenas (utensílios de cerâmica, armas, ferramentas) que permitiram, por exemplo, estimar o tempo de surgimento da agricultura no território ${ }^{\text {IO }}$ e da existência de determinadas sociedades indíge-

9 Para um panorama geral e sucinto da história da arqueologia, vide Robrahn-González (I999). Io A arqueologia já evidenciou que a prática da agricultura entre os povos indígenas do Brasil se iniciou há mais ou menos 4 ou 3 mil anos (Niéde, I998), sendo que a pesca e a caça já eram praticadas 
nas e observar a evolução tecnológica de técnicas, armas e ferramentas. Para a arqueologia, os povos indígenas não "iniciaram” sua existência e história em I500 e, sim, muitos séculos antes da chegada dos portugueses.

\section{Considerações finais}

Em vista da discussão apresentada ao longo do artigo, propõem-se as seguintes medidas ${ }^{\mathrm{II}}$ a serem tomadas para possibilitar a reconstrução da história dos povos indígenas antes e depois do século XVI:

a. É necessário descontruir preconceitos em torno do uso da arqueologia nos estudos da história sobre as sociedades indígenas antes de I5OO, não considerando o seu uso, por exemplo, como mera constatação da existência de uma cultura material ou estudo biológico da evolução do ser humano. Para isso, deve-se intensificar e disseminar o diálogo entre estes dois campos de conhecimento através da criação de grupos de estudos e de pesquisa em universidades que reúnam pesquisadores e estudantes de ambas as áreas; realização de fóruns e seminários que articulem os dois campos na discussão sobre os estudos indígenas; inclusão de disciplinas do curso de Arqueologia no curso de História e vice-versa, visando aproximar os dois campos e desconstruir a falsa noção de que ambos são opostos entre si.

b. A História deve se aproximar, também, de outras esferas do conhecimento, como a etnologia e a etnografia, sendo sugeridas as mesmas propostas anteriores.

c. O indígena deve ocupar papel ativo nos estudos conduzidos sobre sua etnia e demais povos indígenas. Para isso, é necessário que haja uma articulação entre o Estado e as universidades:

Estado: cabe não só o dever de reconhecer os direitos indígenas como, também, o de fiscalizar a não-violação ou negação destes, para que, assim, não haja a marginalização e exclusão dos povos indígenas do acesso e participação na sociedade brasileira. Para que o indígena assuma papel ativo nos estudos relacionados às sociedades indígenas, o Estado deve facilitar seu acesso à edu-

há muito mais tempo: desde cerca de 6 a 8 mil anos a.C., no caso dos povos da Amazônia (UGARTE, 2009).

II As escolhas das medidas propostas basearam-se na pertinência ao conteúdo apresentado, não significando, portanto, que não haja outras, pelo contrário: as medidas propostas representam um ponto de partida para que elas próprias possam ser melhoradas e outras possam ser sugeridas. 
cação via cotas em universidades e construção de escolas e/ou fornecimento de recursos aos povos indígenas para que estes mesmos construam e administrem suas instituições educacionais e de pesquisa.

Universidades: promover aprendizado e estudo das diferentes línguas e etnias indígenas existentes pelo estabelecimento de contato e parcerias com os povos indígenas e criação de núcleos de estudo e pesquisa; incluir uma participação ativa de povos indígenas em pesquisas, grupos de estudo e pesquisa, projetos e demais atividades de ensino, pesquisa e extensão que tratem da temática indígena $^{12}$; promover pesquisas que façam uso da memória e da oralidade para a reconstrução da história dos povos indígenas, permitindo, assim, a produção de pesquisas sob a visão indígena sem deixar de aplicar as práticas científicas na construção de conhecimentos.

d. Por fim, as medidas anteriores e a proposta de construção e inclusão da história dos índios do Brasil a partir do ponto de vista do próprio índio - bem como a utilização de "novos" métodos de investigação neste campo de estudo - só poderão se concretizar efetivamente se o próprio indígena assumir não só o papel ativo neste processo, como, também, a liderança na condução e renovação destes estudos. Para além do reconhecimento do protagonismo indígena na história do Brasil, este deve assumir, ainda, o protagonismo na produção de conhecimento sobre a temática indígena via, por exemplo, ingresso em universidades e instituições públicas, atuação em movimentos políticos em defesa e reconhecimento dos direitos indígenas e apropriação e utilização dos meios de comunicação, das estruturas, ferramentas, conhecimentos, técnicas e tecnologias da sociedade ocidental para enriquecimento das diferentes culturas indígenas - se conveniente - e intensificação de seu protagonismo na produção de conhecimentos sobre sua própria história.

Com a inclusão ativa do indígena na produção acadêmica, espera-se fornecer não só a visão dos povos indígenas sobre suas próprias histórias como, tam-

12 A exemplo de propostas de projetos colaborativos entre indígenas e não-indígenas, pode-se citar a exposição museológica Kaingangs, Terenas e Guaranis, inaugurada em 2018 no Museu de Arqueologia e Etnologia (MAE-USP): "No final de 2OI7 será inaugurada uma nova exposição Kaingangs, Terenas e Guaranis no MAE-USP, que está sendo realizada de forma colaborativa com os três grupos do oeste do estado de São Paulo, por meio da ressignificação das coleções etnográficas salvaguardadas no Museu. Busca-se que os indígenas apresentem em primeira pessoa seus dilemas, lutas e resistências diante da sociedade brasileira" (VASCONCELLOS; GARNEIRO; SILVA, 20I7, p. 8-9). 
bém, eliminar a desvinculação existente entre a história dos índios do Brasil e a história do Brasil que, não raro, marginaliza não só os povos indígenas, como, também, os povos africanos e outros grupos étnicos. A possibilidade de reconstrução da história dos povos indígenas do e antes do século XVI se tornará possível com a adoção e valorização de fontes históricas alternativas como a tradição oral e, consequentemente, a memória - a partir do diálogo com outras áreas do conhecimento, principalmente com a área da arqueologia. Além do mais, este diálogo não só permitirá a utilização de "novas" fontes históricas pela história, como também possibilitará novas leituras e interpretações sobre as fontes já utilizadas.

\section{Referências}

BÔAS, L. V. História, memória e representações sociais: por uma abordagem crítica e interdisciplinar. Cadernos de Pesquisa, São Paulo, v. 45, n. I56, p. 244258, 20I5. Disponível em: 〈https://bit.ly/2vVohNV〉. Acesso em: 20 jul. 2017 .

DEAN, W. A ferro e fogo: a história e a devastação da mata atlântica brasileira. São Paulo: Companhia das Letras, 2004.

FERNANDES, F. A Função Social da Guerra na Sociedade Tupinambá. 2. ed. São Paulo: Edusp/Pioneira, 1970. (Coordenado por Maria Arminda Nascimento Arruda). GODELIER, M. Les tribus dans l'histoire et face aux États. Paris: GNRS Éditions, 2010.

O conceito de tribo: crise de um conceito ou crise dos fundamentos empíricos da Antropologia? In: Horizontes da Antropologia. Lisboa: Edições 70, s/d, p.I3-I6o.

HAMPATÉ BÁ, A. A tradição viva. In: KI-ZERBO, J. (Ed). História geral da África I: metodologia e pré-história da África. 2. ed. Brasília: Unesco, 20I0. p. I672I2. Disponível em: 〈https://bit.ly/2kl6Zqw〉. Acesso em: 25 set. 2017.

GUIDON, N. As ocupações pré-históricas do Brasil (excetuando a Amazônia). In: História dos Índios no Brasil. 2. ed. São Paulo: Companhia das Letras, I998. p. II5-I32. GUNHA, M. G. (Org.).

OLIVEIRA, J. P. Uma etnologia dos “índios misturados”? Situação colonial, territorialização e fluxos culturais. Mana, Rio de Janeiro, v. 4, n. I, p. 47-77, I998. Disponível em: 〈https://bit.ly/2OQbaGe>. Acesso em: 20 jul. 2017.

ROBRAHN-GONZÁLEZ, E. M. Arqueologia em perspectiva: I5O anos de prática e reflexão no estudo do passado. Revista USP, São Paulo, n. 44, p. IO-3I, dez. I999. Disponível em: 〈https://bit.ly/2B6cVMQ〉. Acesso em: 20 jul. 2017. 
SÁ, G. P. Entre a história e a memória, o estudo psicossocial das memórias históricas. Cadernos de Pesquisa, São Paulo, v. 45, n. I56, p. 260-274, 2015. Disponível em: 〈https://bit.ly/2vKTuTK〉. Acesso em: 20 jul. 2017.

SOUSA, G. S. Tratado descritivo do Brasil em 1587. Brasília: Ministério da Educação. Versão digital da primeira edição lançada em I85I, organizada e revisada pelo historiador brasileiro Adolfo de Varnhagen. Disponível em: <https://bit. ly/2vPucUj>. Acesso em: IO set. 2016.

UGARTE, A. S. Sertões de bárbaros: o mundo natural e as sociedades indígenas da Amazônia na visão dos cronistas ibéricos (séculos XVI-XVII). Manaus: Valer, 2009.

VASCONCELlOS, G. M.; CARNEIRO, G. G.; SILVA, M. A. Programa de mediação: estratégias educacionais para recepção de público no MAE/USP. São Paulo: USP, 20I7. Projeto homologado para o Programa Unificado de Bolsas de Estudo para Estudantes de Graduação (PUB 2017/2018) da Universidade de São Paulo.

Ana Carolina Sodré Ferreira é graduanda em História pela Universidade de São Paulo.

ana.sodre.ferreira@usp.br 